\title{
RNA Helicase DDX5 Regulates MicroRNA Expression and Contributes to Cytoskeletal Reorganization in Basal Breast Cancer Cells ${ }^{\star_{[]}}$
}

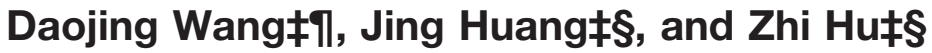

RNA helicase DDX5 (also p68) is involved in all aspects of RNA metabolism and serves as a transcriptional coregulator, but its functional role in breast cancer remains elusive. Here, we report an integrative biology study of DDX5 in breast cancer, encompassing quantitative proteomics, global MicroRNA profiling, and detailed biochemical characterization of cell lines and human tissues. We showed that protein expression of DDX5 increased progressively from the luminal to basal breast cancer cell lines, and correlated positively with that of CD44 in the basal subtypes. Through immunohistochemistry analyses of tissue microarrays containing over 200 invasive human ductal carcinomas, we observed that DDX5 was up-regulated in the majority of malignant tissues, and its expression correlated strongly with those of Ki67 and EGFR in the triplenegative tumors. We demonstrated that DDX5 regulated a subset of MicroRNAs including miR-21 and miR-182 in basal breast cancer cells. Knockdown of DDX5 resulted in reorganization of actin cytoskeleton and reduction of cellular proliferation. The effects were accompanied by upregulation of tumor suppressor PDCD4 (a known miR-21 target); as well as up-regulation of cofilin and profilin, two key proteins involved in actin polymerization and cytoskeleton maintenance, as a consequence of miR-182 down-regulation. Treatment with miR-182 inhibitors resulted in morphologic phenotypes resembling those induced by DDX5 knockdown. Using bioinformatics tools for pathway and network analyses, we confirmed that the network for regulation of actin cytoskeleton was predominantly enriched for the predicted downstream targets of miR-182. Our results reveal a new functional role of DDX5 in breast cancer via the DDX5 $\rightarrow$ miR-182 $\rightarrow$ actin cytoskeleton pathway, and suggest the potential clinical utility of DDX5 and its downstream MicroRNAs in the theranostics of breast cancer. Molecular \& Cellular Proteomics 11: 10.1074/mcp.M111.011932, 1-12, 2012.

From the $¥$ Life Sciences Division, Lawrence Berkeley National Laboratory, Berkeley, California 94720; §Helen Diller Family Comprehensive Cancer Center, University of California, San Francisco, California 94143

Received June 10, 2011, and in revised form, October 13, 2011

Published, MCP Papers in Press, November 15, 2011, DOI 10.1074/mcp.M111.011932
Tumor heterogeneity remains one of the biggest challenges in the diagnosis and therapy of breast cancer (1). Several molecular markers such as estrogen receptor (ER), progesterone receptor (PR), and ErbB2 (HER2/Neu) have been associated with the five major subtypes of breast cancer, defined by the gene-expression clustering as: basal-like, luminal A, luminal B, ErbB2+/ER-, and normal breast-like (2-4). However, molecular pathways leading to the heterogeneity in initiation, progression, prognosis, and clinical outcomes for different tumor subtypes remain elusive. Importantly, there is currently no specific targeted-treatment available against the triple-negative (ER-, PR-, ErbB2-) tumors that constitute the majority of basal-like breast cancers (5). Another major challenge in eradicating breast cancer is the drug resistance derived presumably from the "cancer stem cells," identified as the CD $44^{+} \mathrm{CD} 24^{- \text {/low }} \mathrm{Lin}^{-}$subpopulation (6). However, strategies for specifically targeting cancer stem cells remain to be established. Therefore, identification of new molecular markers of breast cancer, optimally at the single cell level (7), is hotly pursued for its early diagnosis and targeted treatment.

RNA helicase DDX5 (also p68) is a prototypic member of the DEAD (Asp-Glu-Ala-Asp) box family and locates at human chromosome 17q21. Interestingly, chromosome 17 contains multiple functionally important genes in breast cancer including TP53 (17p13), ERBB2 (17q12), and BRCA1 (17q21). For example, BRCA1 deficiency and/or dysfunction have been associated with the triple-negative phenotype (5). DDX5 is up-regulated in various cancers including breast cancer (8-12). In particular, DDX5 is overexpressed in prostate cancer and enhances AR-regulated repression of CD44 splicing (10). However, the functional role of DDX5 in breast cancer remains elusive. Because miRNAs are critically important in cancer (13-16), and DDX5 is involved in miRNA processing and maturation $(17,18)$, we hypothesize that DDX5 regulates miRNAs, either directly or indirectly (e.g. through its interactome), and thereby contributes to breast cancer initiation and progression.

Herein, we describe an integrative biology study linking DDX5 to actin cytoskeleton dynamics via miRNAs in basal breast cancer cells. Our results suggest that targeting DDX5 and its downstream miRNAs might be a novel strategy for theranostics of triple-negative breast cancers. 


\section{EXPERIMENTAL PROCEDURES}

Cell Culture and SILAC Labeling-All breast cancer cell lines were cultured as published (19). Isotopic labeling of breast cancer cells was performed using stable isotope labeling with amino acids in cell culture (SILAC) ${ }^{1}$ kits (Invitrogen, Carlsbad, CA) and verified as we published previously (20).

RNA Interference and MicroRNA Inhibition-Small interfering RNAs (siRNAs) with 3'-dTdT overhangs for human DDX5, ERBB2, and AllStars negative control were obtained from Qiagen (Valencia, CA). The specific sequences for the sense strand for DDX5 and ERBB2 were: 5'-CCGCAACCAUUGACGCCAUTT-3' and 5'-CAAAGAAAUCUUAGACGAATT-3', respectively. All siRNAs were annealed with complementary antisense strands with $3^{\prime}$-dTdT overhangs. Additionally, four FlexTube siRNAs targeting human DDX5 including Hs_DDX5_2, Hs_DDX5_10, Hs_DDX5_11, and Hs_DDX5_13 were ordered directly from Qiagen. Transfection was done with 20-50 nM siRNAs using HiPerFect reagents (Qiagen). Protein lysates were analyzed by Western blotting to confirm the knockdown efficiency. For cell proliferation assays, cells were seeded with a density of $5 \times 10^{4}$ cells per well on 12-well plates and transfected with desired siRNAs. For miRNA inhibitor treatments, miScript miRNA inhibitors including anti-hsa-miR182 and negative control were obtained from Qiagen. Transfection was done with 100-200 nM miRNA inhibitors using HiPerFect reagents. To study cell morphology changes after different treatments, phase-contrast microscopy was performed as described (20).

Quantitative Reverse Transcription-PCR of Mature miRNAs - Total RNA was isolated using Trizol reagent (Invitrogen). For miRNA message analysis, the cDNA was synthesized using the miScript Reverse Transcription Kit (Qiagen). After cDNA conversion, the quantity of mature miR-182 and miR-21 was determined using specific TaqMan real-time PCR miScript primers for miR-182 and miR-21, respectively (Qiagen). Transcription level of endogenous U6 snRNA was used as the internal reference. Real-time PCR was done using miScript SYBR Green PCR Kit (Qiagen) and i-Cycler real-time PCR machine (BioRad, Hercules, CA). Quantitative PCR was done under the following thermocycler conditions: $95^{\circ} \mathrm{C}$ for $15 \mathrm{~min}$, and 40 cycles of $94^{\circ} \mathrm{C}$ for $15 \mathrm{~s}, 55^{\circ} \mathrm{C}$ for $30 \mathrm{~s}$, and $70^{\circ} \mathrm{C}$ for $30 \mathrm{~s}$. All PCR reactions were performed in triplicate. Expression levels of mature mRNAs were evaluated using the comparative cycle-threshold (CT) method (2- $\Delta \Delta C T)$, and results were expressed as relative quantitation (21). For comparison among different cell lines, miR-182 and miR-21 expressions were measured for randomly-selected luminal lines including T47D, BT483, SKBR3, and BT474; Basal A lines including MCF10A, HCC1954, HCC1569, and HCC1500; and Basal B lines including BT549, MDAMB-231, Hs578T, and SUM159T. Results were normalized to those of SUM159T. To determine the effects of DDX5 knockdown using DDX5 siRNAs, results were normalized to those of the siRNA control.

Immunoblotting Analysis of Total Cell Lysates and Subcellular Fractions-Immunoblotting analysis was performed as described (20). Cytoplasmic and nuclear components were isolated using a Qproteome nuclear subfractionation kit (Qiagen). Antibodies used included mouse anti-actin and anti-GAPDH (Chemicon); rabbit anti-p53, antip53(pSer15), anti-ErbB2(pTyr1248), anti-EGFR, anti-cofilin, and antiprofilin-1, and mouse anti-p21 (Cell Signaling, Danvers, MA); rabbit anti-DDX5 and anti-PDCD4 (Bethyl Laboratories, Montgomery, TX); mouse anti-CD44H (R\&D Systems, Minneapolis, MN); rabbit anti-p16

\footnotetext{
${ }^{1}$ The abbreviations used are: SILAC, stable isotope labeling with amino acids in cell culture; LC/MS/MS, liquid chromatography-tandem mass spectrometry; miRNA, microRNAs; siRNA, small interfering RNAs; DAVID, database for annotation, visualization, and integrated discovery; STRING, search tool for the retrieval of interacting genes/ proteins; KEGG, Kyoto Encyclopedia of Genes and Genomes.
}

and anti-ErbB2 (Santa Cruz Biotechnologies, Santa Cruz, CA); mouse anti-E-Cadherin, anti-N-Cadherin, and anti- $\beta$ Catenin (BD Biosciences); and mouse anti-Vimentin (Sigma).

SILAC-based Proteomic Profiling and MicroRNA Profiling-To determine the effects of DDX5 knockdown on global protein expression, we compared the proteome of MDA-MB-231 cells 2 days after transfection with DDX5 siRNA and control siRNA, respectively. Doublelabeled (*Lys, *Arg) and nonlabeled (Lys, Arg) cells were used for transfection with DDX5 siRNA and control siRNA, respectively. Detailed procedures for SILAC-labeling, cell lysis, trypsin digestion, liquid chromatography tandem MS (LC/MS/MS), and data processing were performed as described $(20,22)$. Per MCP guidelines, following are detailed procedures for mass spectrometry: (a) A hybrid quadrupole/orthogonal time-of-flight mass spectrometer, Q-TOF API US mass spectrometer interfaced with a capillary liquid chromatography system (Waters Corp, Milford, MA) was used for all protein identifications and quantitation; (b) Mass spectra were processed using MassLynx 4.0 software, and proteins were identified using Protein Global Sever 2.0 software. The protein identities were further confirmed by Mascot (http://www.matrixscience.com) (Version 2.2) using the MS/MS peak lists exported from MassLynx. The mass tolerance for precursor ions and fragment ions was $0.5 \mathrm{Da}$ and the charge states $(+2,+3,+4)$ were considered for precursor ions; (c) The Swiss-Prot database (Release 2010_9 with 519,348 entries) with species restricted to Homo sapiens (human) were used for the search. For proteins with only one peptide sequenced, three criteria were used in the final identification following manual interpretation of the MS/MS data: Mascot score is more than 30, a minimum of four consecutive b or $y$ ions present in the MS/MS spectra, and the relative protein mobility on SDS-PAGE gels fits its theoretical molecular weight; (d) The enzyme specificity considered was trypsin only and the maximum missed-cleavage permitted was 1; (e) Protein modifications considered included carbamidomethylation of cysteine (fixed), N-terminal acetylation, N-terminal Gln to pyroGlu, oxidation of methionine, and phosphorylation of serine, threonine, and tyrosine; (f) For SILAC quantitation, the light (Lys and Arg) and heavy (*Lys and ${ }^{*}$ Arg) pair of the tryptic peptides were identified by Mascot using the option: SILAC $K+6 R+10$ [MD]. The relative expression of the light/ heavy peptide pairs was determined by peak intensity ratios extracted from the LC-MS spectra with both peptides presented. The average and standard deviation (STDEV) of the relative expression for corresponding protein pairs were calculated using the values from their confirmed peptide pairs (minimum of 2). Relative quantitation for selected proteins was further confirmed by Western blotting analyses as described above.

To detect changes in global miRNA expression after DDX5 knockdown, we performed miRNA profiling using miRCURY ${ }^{\mathrm{TM}}$ LNA Array (fifth version, Exiqon). Total RNA was isolated from MDA-MB-231 cells after transfection with DDX5 siRNA, control siRNA, and negative control (transfection mix only), respectively, using the miRCURY'TM RNA isolation kit. The quality of total RNA was verified by an Agilent 2100 Bioanalyzer. Total RNA from the three individual samples and reference (common reference pool of the three samples) was labeled with $\mathrm{Hy} 3^{\mathrm{TM}}$ and $\mathrm{Hy}^{\mathrm{TM}}$ fluorescent labels, respectively, using the miRCURYTM LNA Array power labeling kit (Exiqon). The Hy3 $3^{\mathrm{TM}}$-labeled samples and a Hy5 $5^{\mathrm{TM}}$-labeled reference RNA sample were mixed pair-wise and hybridized to the miRCURY'TM LNA Array, which contains capture probes targeting all miRNAs for human, mouse or rat registered in the miRBASE version 15.0 at the Sanger Institute. The hybridization was performed according to the miRCURYTM LNA array manual using a Tecan HS4800 hybridization station (Tecan, Austria). The microarray slides were scanned using the Agilent G2565BA Microarray Scanner System and the image analysis was carried out using the ImaGene 8.0 software (BioDiscovery Inc.). The quantified 
signals were background-corrected (Normexp with offset value 10) (23) and normalized using the global Lowess (LOcally WEighted Scatterplot Smoothing) regression algorithm. The unsupervised hierarchical clustering was performed on log2(Hy3/Hy5) ratios, which passed the filtering criteria on variation across samples.

Immunohistochemistry for Tissue Microarrays of Primary Human Breast Tumors - Tissue microarrays BRC1501, 1502, and 1503 containing primary human breast tumors were obtained from Pantomics. The EDTA buffer/pressure cooker method was used for antigen retrieval following standard protocols. We optimized the staining conditions for DDX5 using universal IHC/ISH control tissue arrays (UNC241). For single staining of BRC1501, 1502, and 1503, the rabbit polyclonal anti-DDX5 antibody (Bethyl Laboratories) and a polymerbased detection system were used. For double-staining of BRC1501, a MultiVision Polymer Detection System (Thermo Scientific) was used. The primary antibodies used were (1) rabbit polyclonal antiDDX5 antibody, detected in blue; and (2) mouse monoclonal antiERBB2 antibody c-erbB-2 [CB11] (Biocare Medical), detected in red. Rabbit polyclonal anti-pan cytokeratin (Z0622, DAKO) and normal rabbit sera (X0902, DAKO) were used as the positive and negative controls, respectively. Staining intensities were manually scored by pathologists and assigned a score in the range between 0 and 4.0 with an increment of 0.5 .

Statistical Analysis and Bioinformatics-ANOVA test was performed to examine the DDX5 protein expression among different subtypes (Lu, BaA, and BaB) of breast cancer cell lines. Pearson's correlation test was performed to examine the relationship between the protein expression of DDX5 and those of other markers including CD44 in breast cancer cell lines. Continuity Correction Chi-Square tests were performed to examine the DDX5 positive staining $(\geq 2.0)$ among benign and malignant human breast tissues. Kendall's Tau_b test was performed to examine the relationship between DDX5 and other clinical characteristics, including age, tumor grade and stage, ER, PR, ERBB2, p53, EGFR, and Ki67 status, for human primary breast tumors. Standard deviation (s.d.) was calculated for triplicate experiments. Student's $t$ test was performed to confirm specific differences between treatment conditions $(p<0.05, n=3)$. A two-tailed $p$ value of less than 0.05 was considered to indicate statistical significance. All analyses were performed using SPSS 11.5.0 for Windows and Microsoft Excel.

Bioinformatics was performed using public databases. Proteinprotein interaction network for DDX5 was generated using search tool for the retrieval of interacting genes/proteins (STRING). Targets of miR-182 were predicted using TargetScan. Pathway and network analyses for the predicted miR-182 target gene list were performed using database for annotation, visualization, and integrated discovery (DAVID). Pathway information was generated using Kyoto Encyclopedia of Genes and Genomes (KEGG).

\section{RESULTS}

DDX5 Protein Expression is Distinct Among Different Subtypes of Breast Cancer Cells-We measured the protein expression pattern of DDX5 for a panel $(n=45)$ of breast cancer cell lines. Fig. $1 A$ shows the Western blots of DDX5 and p53 for 38 cell lines, along with those of ESR1, ErbB2, EGFR, and CD44 published previously (19). The relative DDX5 expression in each cell line was normalized to that in MCF12A, and clustered according to the three subtypes classified previously: luminal (Lu), basal A (BaA), and basal B (BaB) (19). There was significant difference among the three groups (ANOVA, $p=0.002$ ) (Fig. $1 B$ ). In particular, the average relative expression of DDX5 increased progressively from luminal to basal subtypes with basal $B$ cell lines having the highest value (mean $=0.66,0.93$, and 1.17 for $\mathrm{Lu}, \mathrm{BaA}$, and $\mathrm{BaB}$, respectively). We investigated whether there was a correlation between DDX5 and other key markers in Fig. $1 A$. Strikingly, we observed a positive correlation between DDX5 and CD44 for the cell lines $(n=10)$ showing detectable CD44 expression (Fig. 1C, Pearson's correlation, $r=0.6925, p<0.05$, twotailed). Furthermore, all of these CD44+ lines belong to the basal subtypes. Therefore, DDX5 is one of the molecular markers manifesting the breast cancer heterogeneity: (1) its expression pattern is distinct among different subtypes; (2) its high expression is associated predominantly with the more aggressive basal subtypes; and (3) its expression correlates strongly to that of CD44 for the basal subtypes, presumably as a result of the enhanced repression of CD44 splicing (10).

DDX5 is Up-regulated in Invasive Human Breast Cancers and Correlates to Ki67 and EGFR in Triple-Negative Tumors - To understand the in vivo role of DDX5 in breast cancer, we determined DDX5 protein expression in over 200 human breast tumors using tissue microarrays. A comprehensive database of age, sex, histology, tumor grade and stage, along with other pathological factors including ER, PR, ErbB2, p53, EGFR, and Ki67, evaluated by immunohistochemistry, was available for these tumors. We observed weak to strong nuclear staining of DDX5 in epithelial cells in the majority of benign and malignant breast tissues (Fig. 2A). Weak to moderate nuclear staining was also observed in most of the stromal cells. Strong nuclear staining of DDX5 (intensity $=2.0$ and above) was observed in $79.4 \%$ (54/68) of the malignant breast tumors; in contrast, only one fibroadenoma among the five normal/benign conditions of the breast showed the medium nuclear staining (intensity $=1.5$ ) (Fig. $2 B$ ). Consistently, the DDX5 positive rate (intensity $=2.0$ and above) was significantly higher in malignant $(79.4 \%)$ than in benign $(0 \%)$ tissues (Continuity Correction Chi-Square Tests, $p=0.001$ ).

We next determined whether there was any correlation between DDX5 and ER, PR, ErbB2, EGFR, p53, and Ki67 in tumors. Typically, triple-negative (i.e. basal-like) and ErbB2+ tumors account for $\sim 15 \%$ and $\sim 20-30 \%$ of breast carcinomas, respectively. To have a better representation of the triple-negative tumors, we performed immunohistochemistry of DDX5 and other markers for a total of $\sim 205$ invasive ductal carcinomas, among which $24(\sim 12 \%)$ were triple-negative (Table I). Strikingly, DDX5 correlated strongly with Ki67 among all tumors $(r=0.357, p<0.001)$ as well as triple-negative tumors ( $r=0.491, p=0.003$ ). We observed a positive correlation between DDX5 and ErbB2 among all tumors $(r=$ $0.143, p=0.009)$, consistent with what had been reported before (11). We observed positive correlations between DDX5 and p53, and between DDX5 and ER, but not between DDX5 and age, or between DDX5 and PR. This is consistent with previous studies showing that DDX5 is a potent transcriptional coactivator of ESR1 (24) and p53 (25). For triple-negative tumors, we observed EGFR expression in $\sim 50 \%$ cases, and 

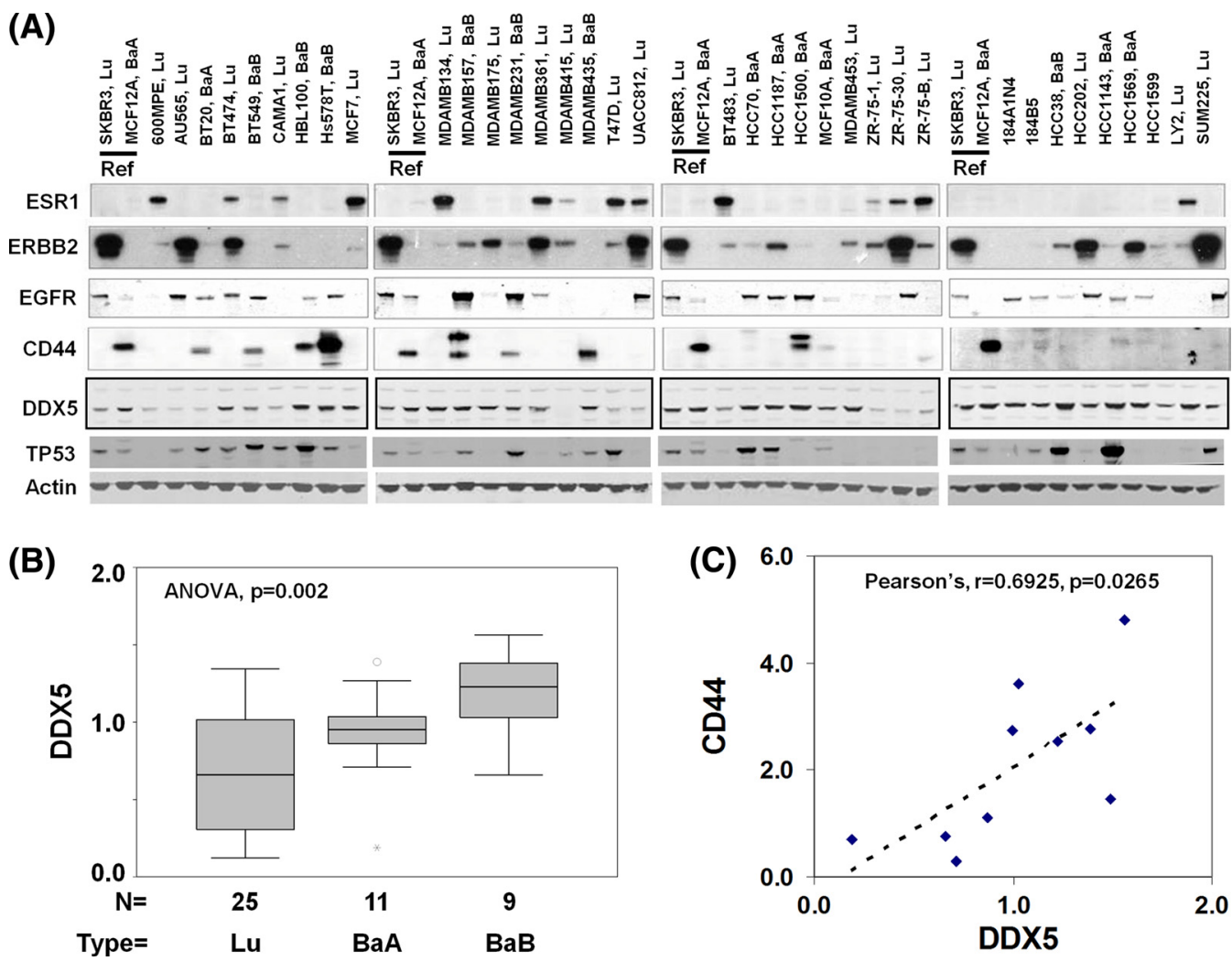

FIG. 1. DDX5 protein expression in human breast cancer cell lines. $A$, Western blotting analysis of ESR1, ErbB2, EGFR, CD44, DDX5, and TP53 in a panel of breast cancer cell lines. Corresponding known subtypes (Lu, BaA, and BaB) were labeled for each cell line. Actin was used as the loading control. SKBR3 and MCF12A (underlined with "Ref") were used as the reference cell lines for normalization between different blots. $B$, Quantitation and clustering of the relative expression of DDX5 among the three subtypes (ANOVA test, $p<0.01$ ). $C$, Correlation between the relative expression of DDX5 and CD44 in the 10 basal cell lines showing detectable CD44 expression in (A) (Pearson's correlation, $p<0.05)$.

furthermore, there is a positive correlation between DDX5 and EGFR ( $r=0.395, p=0.019, n=24)$. Consistently, EGFR protein expression was reported in $54 \%$ of basal-like breast cancers and associated with the poor survival independent of nodal status and size (26). Somewhat surprisingly, we observed an inverse correlation between DDX5 and tumor stage among all tumors $(r=-0.174, p=0.002, n=205)$ and triple-negative tumors ( $r=-0.459, p=0.007, n=24)$. Therefore, DDX5 is up-regulated in invasive breast cancers and correlates to key clinical markers such as Ki67 and EGFR.

Knockdown of DDX5 Induces Reorganization of Actin Cytoskeleton in Basal Breast Cancer Cells-To directly assess the functional role of DDX5 in breast cancer cells, we knocked down DDX5 in two representative basal B cell lines: Hs578T and MDA-MB-231. We achieved knockdown of $\sim 76$ and $\sim 85 \%$, for Hs578T and MDA-MB-231, respectively (Fig. 3C). We observed clear morphological changes, indicating cytoskeletal reorganization, after DDX5 knockdown (Fig. 3A). Cells became more rounded and less spindle-like. These phenotypes resembled those of mesenchymal-to-epithelial transition, the reverse process of epithelial-to-mesenchymal transition that induces cytoskeletal reorganization and promotes cancer invasion and metastasis (27). On the other hand, we did not observe clear morphological changes after DDX5 knockdown in luminal cell lines such as MCF7 and SKBR3 (data not shown). However, knockdown of DDX5 did not alter the expression of $\mathrm{N}$-cadherin, E-cadherin, vimentin, or $\beta$-catenin for the cell lines tested above (data not shown), suggesting that the cytoskeletal reorganization after DDX5 knockdown was not because of mesenchymal-to-epithelial transition (28). We reasoned that instead actin dynamics might contribute to the observed morphological changes. Indeed, we observed a significant increase of nuclear but not cytoplasmic actin after DDX5 knockdown in MDA-MB-231 cells (Fig. 3B).

To confirm that the cytoskeletal changes after DDX5 knockdown was not because of any off-target effects, we knocked down DDX5 in MDA-MB-231 cells using four additional siRNAs targeting different regions of the DDX5 sequence, respectively. As shown in supplemental Fig. S1A, transfection of the five siRNAs individually resulted in different degrees of DDX5 knockdown under identical conditions. In particular, our customarily-designed one (p68 siRNA) and Hs_DDX5_10 achieved similar and the most efficient knockdowns, with $\sim 53$ and $\sim 51 \%$, respectively. Because p68 siRNA and Hs_DDX5_10 targeted two completely distinct regions of 
(A)
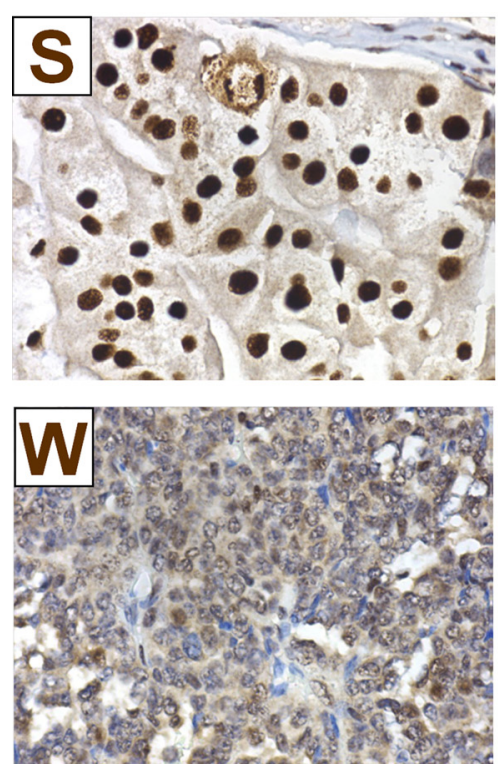

(B)

(i)

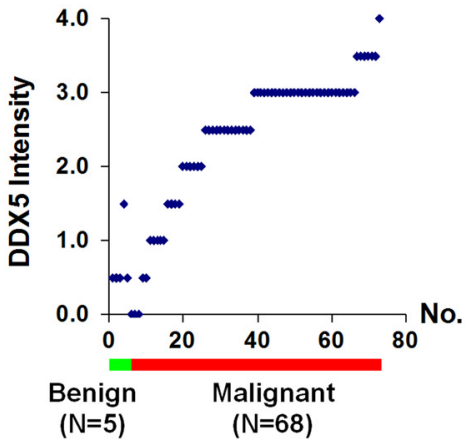

(ii)

\begin{tabular}{cccc}
\hline & \multicolumn{2}{c}{ DDX5 $(\geq 2.0:+)$} & p value \\
\hline Benign & $5(100.0 \%)$ & $0(0.0 \%)$ & 0.001 \\
& & & \\
Malignant & $14(20.6 \%)$ & $54(79.4 \%)$ & \\
& & & \\
\hline
\end{tabular}

FIG. 2. DDX5 protein expression in human breast cancer tissues. $A$, Immunohistochemistry images of tissue microarrays, showing representative strong (S) and weak (W) nuclear staining of DDX5 in primary human breast tissues. $B$, Quantitation of DDX5 staining intensity on a tissue microarray containing five normal/benign fibroadenoma and 68 malignant tumors (b-i), and the corresponding statistical analysis of DDX5 staining in benign and malignant tissues (b-ii) (Continuity Correction Chi-Square Tests, $p=0.001)$. DDX5 intensity scored at 2.0 or above was defined as the positive staining (+).

TABLE I

Correlation between DDX5 protein expression and other clinical features for invasive human primary breast cancers ${ }^{*} p<0.05,{ }^{* *} p<0.01$, two-tailed

\begin{tabular}{|c|c|c|c|c|c|c|c|c|c|c|}
\hline Tumors & $\mathrm{n}$ & Kendall's tau_b Test & Ki67 & EGFR & TP53 & ERBB2 & PR & ER & Stage & Grade \\
\hline \multirow[t]{2}{*}{ Triple-negative } & 24 & $\mathrm{R}$ Value & 0.491 & 0.395 & 0.344 & - & - & - & -0.459 & -0.224 \\
\hline & & p Value & $0.003^{\star *}$ & $0.019^{*}$ & $0.043^{*}$ & - & - & - & $0.007^{\star *}$ & 0.196 \\
\hline All tumors & 205 & $\mathrm{R}$ Value & 0.357 & 0.016 & 0.180 & 0.143 & 0.029 & 0.129 & -0.174 & -0.134 \\
\hline
\end{tabular}

DDX5, 231nt-249nt, and 1622nt-1642nt, respectively, we next determined whether they induced the same cytoskeletal changes in MDA-MB-231 cells. As shown in supplemental Fig. S2, cells became more rounded and less spindle-like 2 days after transfection of both siRNAs, respectively. Therefore, our results strongly suggest that reduction of DDX5 protein expression contributes to the cytoskeletal reorganization in MDA-MB-231 cells.

To gain mechanistic insights into the cytoskeletal reorganization after DDX5 knockdown, we performed large-scale SILAC-based proteomic analyses of MDA-MB-231 cells. We focused on key components of the cytoskeleton such as actin and actin-related proteins. Strikingly, we observed significant increases in both cytoplasmic profilin and cofilin after DDX5 knockdown (Table II). Fig. $3 C$ (i) shows a representative MS spectrum for the light/heavy pair of a tryptic peptide (aa92aa105) from human profilin-1: (92)STGGAPTFNVTVTK(105). On average, we detected a 2.2- and 2.3-fold increase for profilin and cofilin, respectively, after DDX5 knockdown (Fig. $3 C$ (ii)). The increases were confirmed by the Western blotting analysis for both Hs578T and MDA-MB-231 cells (Fig. 3C (iii)). We also confirmed on average 2.5-fold increase of nuclear (monomeric) actin after DDX5 knockdown in the nuclear fraction of MDA-MB-231 cells; in comparison, no significant changes were observed for other representative nuclear proteins such as DNA-PKcs and Top2A, or the nuclear fraction of annexin A2 and cofilin (Fig. 3D and Table II). Cofilin and profilin are important for actin polymerization and stabilization, and thus, cytoskeleton maintenance. Therefore, the cytoskeletal reorganization and nuclear shuffling of monomeric actin after DDX5 knockdown might arise from the up-regulation of cofilin and profilin.

MiR-182 is Responsible for the Cytoskeletal Reorganization after DDX5 Knockdown-To understand the mechanism underlying the cytoskeletal reorganization, we performed global miRNA profiling of MDA-MB-231 cells. As shown in Fig. $4 A$, the dominant change after DDX5 knockdown was the downregulation of a subset of miRNAs, including miR-21 and multiple Let-7s (Let-7a, Let-7d, Let-7f, Let-7g, and Let-7i). We confirmed that these changes were not because of cell cycle 
(A) +siRNA
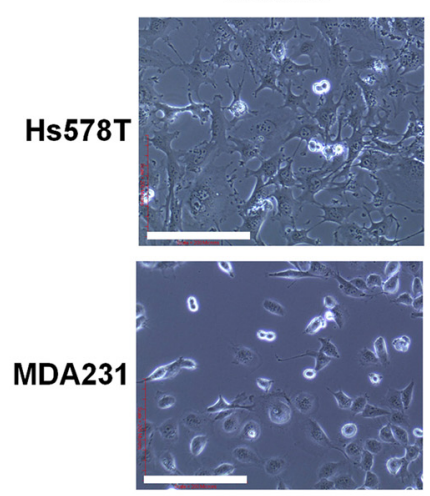

(B)

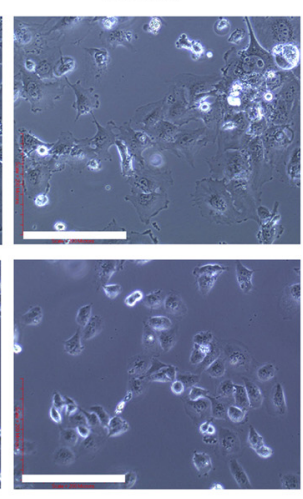

(i)

(ii)
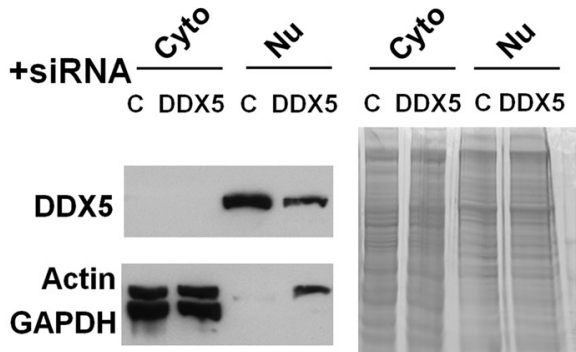

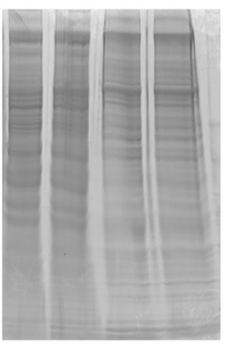

(C)

(i)

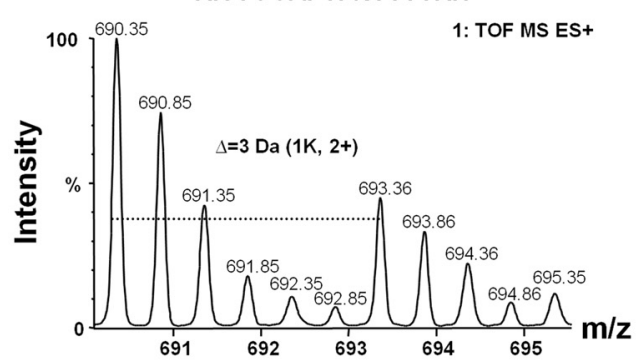

(ii)

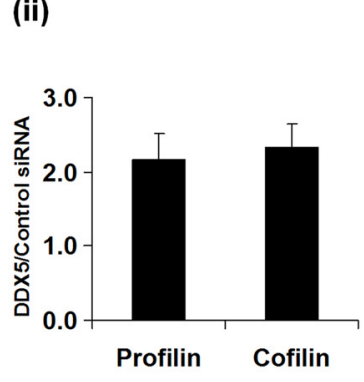

(iii)

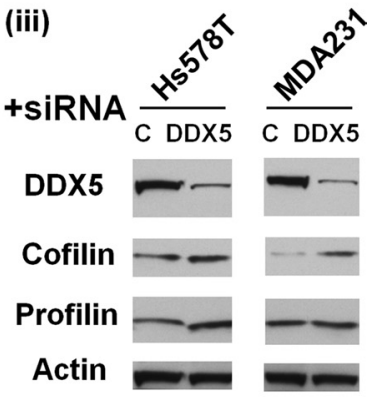

(D)

Nuclear fraction

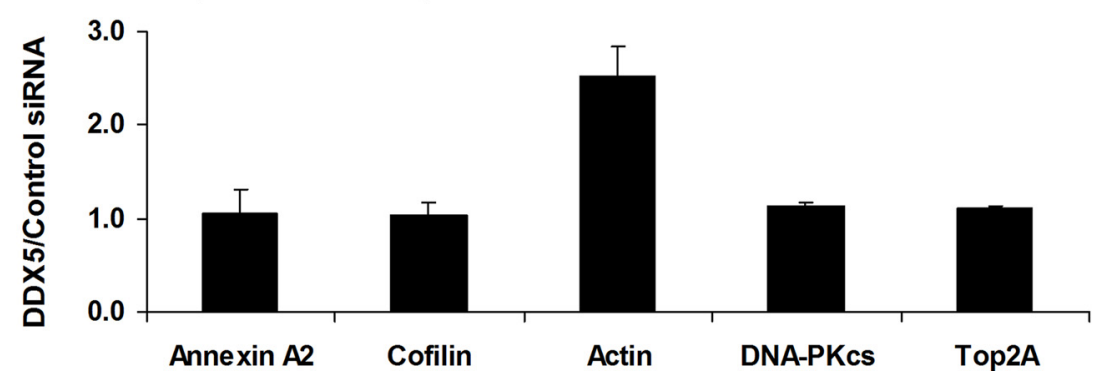

FIG. 3. Effects of DDX5 knockdown on actin cytoskeleton in basal breast cancer cell lines. $A$, Phase-contrast images showing morphological changes of Hs578T and MDA-MB-231 cells, 2 days after transfection with DDX5 and control siRNAs, respectively. Scale bar: $200 \mu \mathrm{m}$. B. Western blotting analysis of actin and DDX5 in the cytoplasmic and nuclear fractions of MDA-MB-231 cells, 2 days after transfection with DDX5 and control siRNAs, respectively (b-i); also shown is the corresponding Coomassie blue-stained gel image (b-ii). Cyto: cytoplasm; Nu: nuclei; C: control siRNA. C, (c-i) Mass spectrum of the SILAC light/heavy pair for the peptide aa92-aa105 from human profilin-1, obtained from the 1:1 mix of light (+DDX5 siRNA) and heavy (+ control siRNA) total cell lysates of MDA-MB-231 cells; (c-ii) SILAC quantitation of profilin and cofilin for MDA-MB-231 cells after transfection with DDX5 siRNA relative to control siRNA; and (c-iii) Western blotting analysis of DDX5, cofilin, and profilin in Hs578T and MDA-MB-231 cells, 2 days after transfection with DDX5 and control siRNAs, respectively. D, SILAC quantitation of annexin A2, cofilin, actin, DNA-PKcs, and Top2A in the nuclei, obtained from the 1:1 mix of light (+DDX5 siRNA) and heavy (+ control siRNA) nuclear fractions of MDA-MB-231 cells. Error bars: s.d. $(n=3)$.

arrest because we did not observe corresponding changes in protein expressions of either p21 or p16 (two key markers for cell cycle arrest and cellular senescence (20)) (data not shown). Indeed, DDX5 directly unwinds the human Let-7 miRNA precursor duplex (29). Therefore, DDX5 knockdown would reduce Let-7s processing and maturation. Because miR-21 is crucial for tumorigenesis and metastasis, and tumor suppressor gene PDCD4 is a confirmed miR-21 target both in vitro $(30,31)$ and in vivo $(32)$, we examined whether PDCD4 was up-regulated after DDX5 knockdown. As expected, PDCD4 was significantly up-regulated in both basal B cell lines (Fig. 4B), in agreement with the miR-21 down-regulation.

Using the TargetScanHuman 5.1 (http://www.targetscan. org), we searched for other gene targets for each miRNA regulated by DDX5 knockdown, as well as potential miRNAs specifically targeting cofilin and/or profilin. Interestingly, we 
TABLE II

MS identification and quantitation of selected proteins in MDA-MB-231 cells

\begin{tabular}{|c|c|c|c|c|c|c|c|}
\hline Protein name & $\begin{array}{c}\text { Swiss-Prot } \\
\text { accession No. }\end{array}$ & $\begin{array}{l}\text { Subcellular } \\
\text { location } \\
\text { measured in } \\
\text { this study }\end{array}$ & $\begin{array}{c}\text { Number of } \\
\text { unique peptides } \\
\text { identified by } \\
\text { MS/MS }\end{array}$ & $\begin{array}{l}\text { Sequence } \\
\text { coverage }\end{array}$ & $\begin{array}{c}\text { Number of } \\
\text { unique peptides } \\
\text { used for } \\
\text { quantitation }\end{array}$ & $\begin{array}{c}\text { Ratio: } \\
\text { DDX5/Control } \\
\text { siRNA }\end{array}$ & STDEV \\
\hline Cofilin & P23528 & Cytoplasmic & 9 & $64 \%$ & 3 & 2.34 & 0.30 \\
\hline Cofilin & P23528 & Nuclear & 4 & $38 \%$ & 2 & 1.04 & 0.14 \\
\hline Annexin A2 & P07355 & Nuclear & 20 & $68 \%$ & 7 & 1.05 & 0.26 \\
\hline TOP2a & P11388 & Nuclear & 9 & $6 \%$ & 2 & 1.11 & 0.03 \\
\hline
\end{tabular}

identified miR-182 as a good match. The predicted consequential pairing of the target region and miR-182 sequence shows that cofilin has a 8 mer pairing, whereas profilin has a 7mer-1A pairing (data not shown). The only other predicted miRNAs with consequential pairing to both cofilin and profilin are miR-96/1271. However, they have 7 mer-1A pairings for both genes, and were not regulated by DDX5 knockdown (Fig. 4A).

We next examined whether there was a direct correlation between the DDX5 protein expression and the level of miR182 and miR-21 among 12 representative breast cancer cell lines ( 3 of $\mathrm{Lu}, \mathrm{BaA}$, and $\mathrm{BaB}$ each). We did not observe a clear correlation between DDX5 and miR-21, or between DDX5 and miR-182, suggesting that DDX5 was not the sole factor regulating these miRNAs. This is because of the fact that multiple factors are involved in miRNA processing and maturation. However, we observed a positive correlation between miR182 and miR-21 ( $r=0.77, p=0.003$ ) (Fig. 4C), consistent with an earlier study showing that miR-21 and miR-182 are overexpressed and correlated in cancer cell lines (33).

Using qRT-PCR, we further confirmed that miR-182 was downregulated after DDX5 knockdown in MDA-MB-231 cells, with a concurrent reduction in cell proliferation (Fig. 4D). Again, we confirmed that this was a direct effect of DDX5 knockdown because transfection of p68 siRNA and Hs_DDX5_10 respectively induced similar reduction of miR182 in MDA-MB-231 cells (supplemental Fig. S1B). To validate whether miR-182 was responsible for the increase of cofilin and profilin after DDX5 knockdown, we performed miRNA inhibitor experiments. Inhibition of miR-182 induced observable morphological changes in both MDA-MB-231 and Hs578T cells (Fig. 4E), resembling those induced by the DDX5 knockdown (Fig. 3A). Consistently, inhibition of miR-182 significantly increased the protein expressions of cofilin and profilin, without altering those of DDX5 and p53 (Fig. 4F).

The Network for Regulation of Actin Cytoskeleton is Predominantly Enriched for the Predicted Downstream Targets of miR-182-To directly link DDX5 with actin cytoskeleton dynamics via miR-182, we performed bioinformatics analysis of pathways and networks for miR-182 targets. Among the networks regulated by the predicted miR-182 targets, the top 2 hits were: (1) regulation of actin cytoskeleton (24 counts, $p$ value $=3.7 \mathrm{E}-5)$ (Fig. 5), and (2) pathways in cancer (29 counts, $p$ value $=3.0 \mathrm{E}-4)$. The former contains cofilin (CFN) and profilin (PFN), both of which were identified as the potential direct targets of miR-182 by our SILAC-proteomics and functional studies described above. On the other hand, pathways in cancer, but not regulation of actin cytoskeleton, was also one of the top-hit pathways for the predicted miR-21 targets (10 counts, $p$ value $=0.02$ ).

\section{DISCUSSION}

RNA helicase DDX5 is essential for early organ development and maturation, and its knockout in mice results in embryonic lethality (34). DDX5 is multifunctional and involved in a diverse array of biological processes including cell proliferation, differentiation, and apoptosis (35). However, the exact role of DDX5 in breast cancer has not been elucidated. We propose a working model based on this study (Fig. 5): DDX5 serves as a master regulator for a subset of miRNAs, which modulate their respective downstream targets (e.g. PDCD4 via miR-21, cofilin and profiling via miR-182) at transcriptional and/or translational levels (36), and consequently, contributes to breast cancer initiation and progression; the process depends on cellular contexts, particularly the interaction between DDX5 and other key players in tumor biology, including ESR1, TP53, HDAC1, and EP300, i.e. the DDX5 interactome (35); furthermore, the DDX5 interactome is finetuned by its post-translational modifications ("PTMs"), such as phosphorylation (37), acetylation (38), ubiquitination (8), and sumoylation (39), which collectively regulate DDX5 stability, intracellular location, and ATPase and/or helicase activity.

Our results shed new light on how DDX5 contributes to the basal phenotype of breast cancer. We show that DDX5 correlates positively with p53 and EGFR; and more strongly with Ki67, a nuclear marker for cellular proliferation indicating poor prognosis and invasiveness of tumors $(40,41)$, as well as a high risk of relapse and a worse survival in patients with early breast cancer (42). Indeed, basal-like breast cancers usually have high expression of p53 (43), EGFR (26, 44), and Ki67 (45). This presumably provides the cellular context for DDX5 interactome in basal (but not luminal) breast cancer cells. We show 
(A)

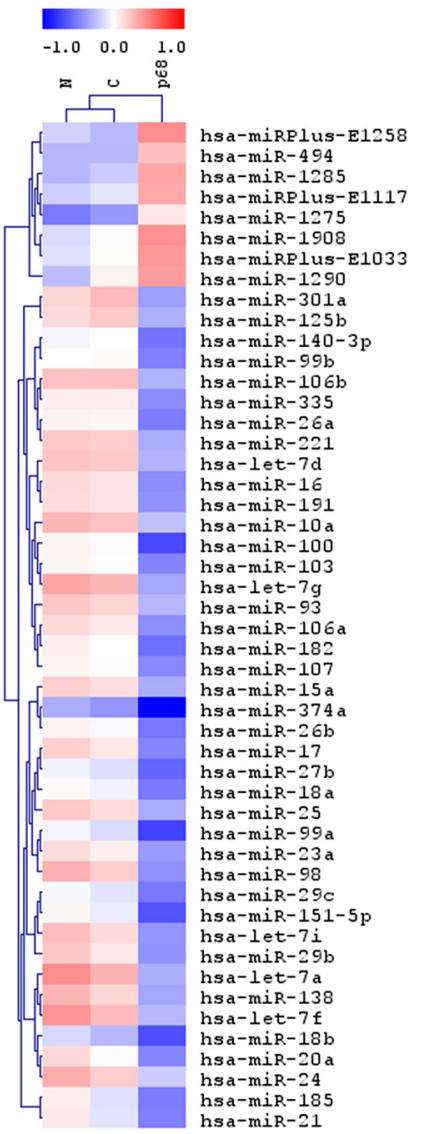

(B)

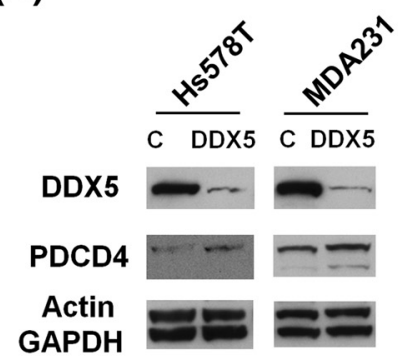

(C) Pearson's, $r=0.77, p=0.003$

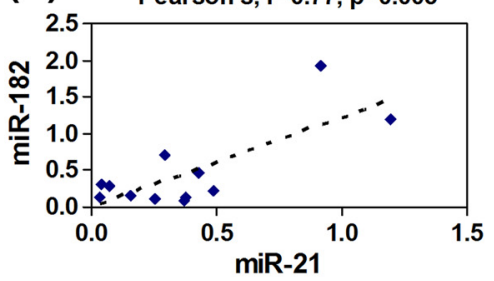

\begin{tabular}{ll|}
$\square$ Cell Number \\
$\square$ miR-182
\end{tabular}

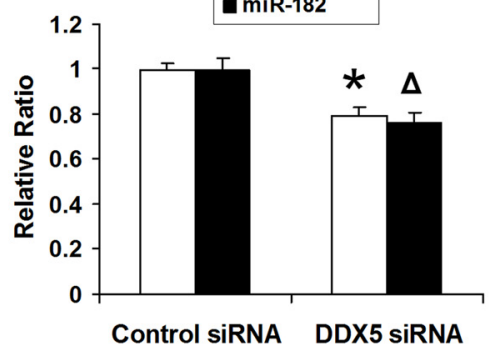

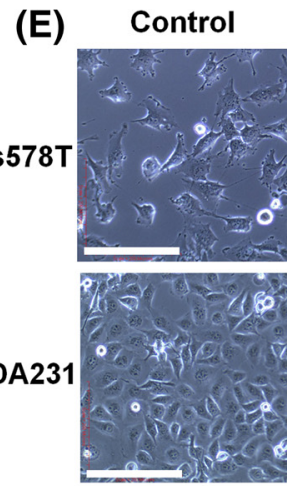

$+\alpha-\operatorname{miR}-182$
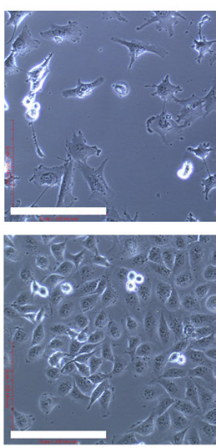

(F)

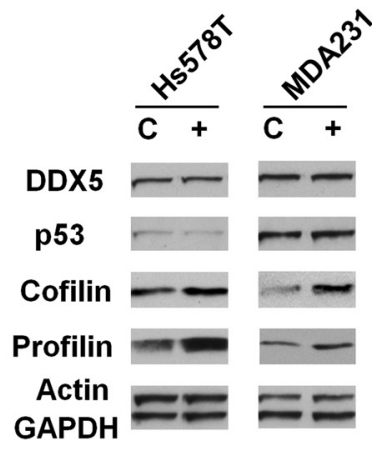

FIG. 4. Effects of DDX5 knockdown on miRNA expression in basal breast cancer cell lines. $A$, miRNA profiling and cluster analysis of miRNAs from MDA-MB-231 cells transfected with negative control ( $N$, transfection mix only), control siRNA (C), and DDX5 siRNA (p68), respectively. Heat-map shows up- and down-regulation (red versus blue). The clustering was performed on log2 (Hy3/Hy5) ratios that passed the filtering criteria on variation across samples. $B$, Western blotting analysis of PDCD4 after DDX5 knockdown in Hs578T and MDA-MB-231 cells, respectively. $C$, Correlation between miR-21 and miR-182 relative expressions in a panel of 12 cell lines (4 Lu, $4 \mathrm{BaA}$, and $4 \mathrm{BaB})$, as quantified by qRT-PCR (Pearson's correlation, $p<0.05$ ). $D$, Relative expression of miR-182 in MDA-MB-231 cells, 2 days after transfection with DDX5 and control siRNAs, respectively. Also shown are the corresponding relative cell numbers 4 days after the transfection. Error bars: s.d. $(n=3)$; ${ }^{*}$ and $\Delta$ : Student's $t$ test $(p<0.05, n=3)$. E, Phase-contrast images showing morphological changes of Hs578T and MDA-MB-231 cells, 2 days after transfection with miScript inhibitors for miR-182 and negative control, respectively. Scale bar: $200 \mu \mathrm{m}$. $F$, Western blotting analysis of DDX5, p53, cofilin, and profilin in Hs578T and MDA-MB-231 cells, 2 days after transfection with miScript inhibitors for miR-182 (+) and negative control $(\mathrm{C})$, respectively. Actin and GAPDH were used as the loading control.

an inverse correlation between DDX5 and the tumor stage. Although this is counterintuitive, tumors in the early stage (i.e. smaller sizes) might have a higher percentage of "cancer stem cells," and therefore, higher DDX5 expression. This agrees with our observation that in basal cells DDX5 strongly correlates with CD44, a presumed marker for cancer stem cells. Consistently, DDX5 was shown to be one of the only two drug resistance genes, out of the nearly 1000 proteins monitored in individual lung cancer H1299 cells (46). Importantly, we demonstrate that DDX5 up-regulates a subset of miRNAs including miR-21 and miR-182. Interestingly, miR-21 locates at human chromosome 17q23.2, adjacent to 17q21 where DDX5 locates. Furthermore, miR-21 is an oncogene in vivo $(32,47)$. MiR-182 is broadly conserved in vertebrates and has also been linked to cancer. For example, it is up-regulated in human melanoma and promotes metastasis (48). It regulates FOXO1 in breast cancer cells (49), is overexpressed in lung primary tumors (50), and serves as a prognostic marker for glioma progression and patient survival (51). Furthermore, miR-182 is one of the miRNAs regulated in HCT116 cells after DOX treatment (18). In this study, we show mechanistically that miR-182 is regulated by DDX5, and that miR-182 may directly control the expression of cofilin and profilin, both of which modulate actin cytoskeleton and contribute to cancer cell proliferation and invasion $(52,53)$. Therefore, DDX5 may promote drug resistance and invasion of breast cancer cells by diminishing cofilin- and profilin-dependent actin polymerization via miR-182. Very recently, while our manuscript was in preparation, Moskwa et al. showed that miR-182 down-regulates BRCA1 in basal breast cancer 


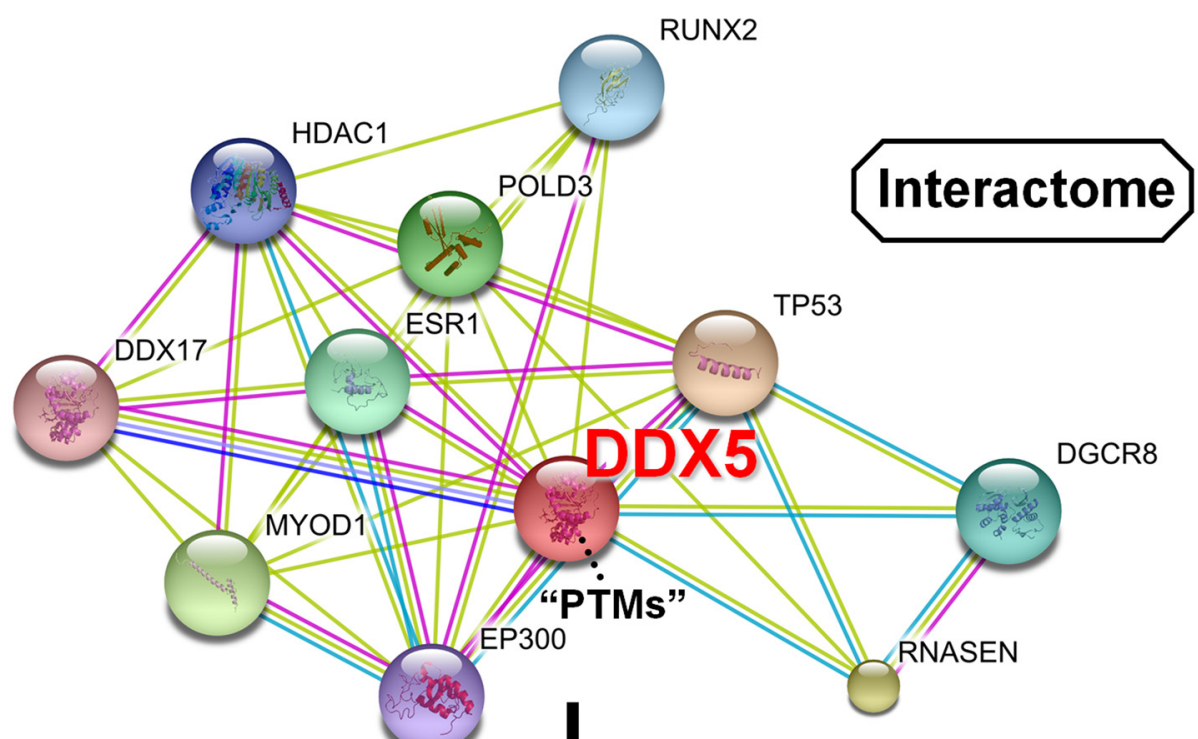

miR-182

\section{Regulation of actin cytoskeleton}

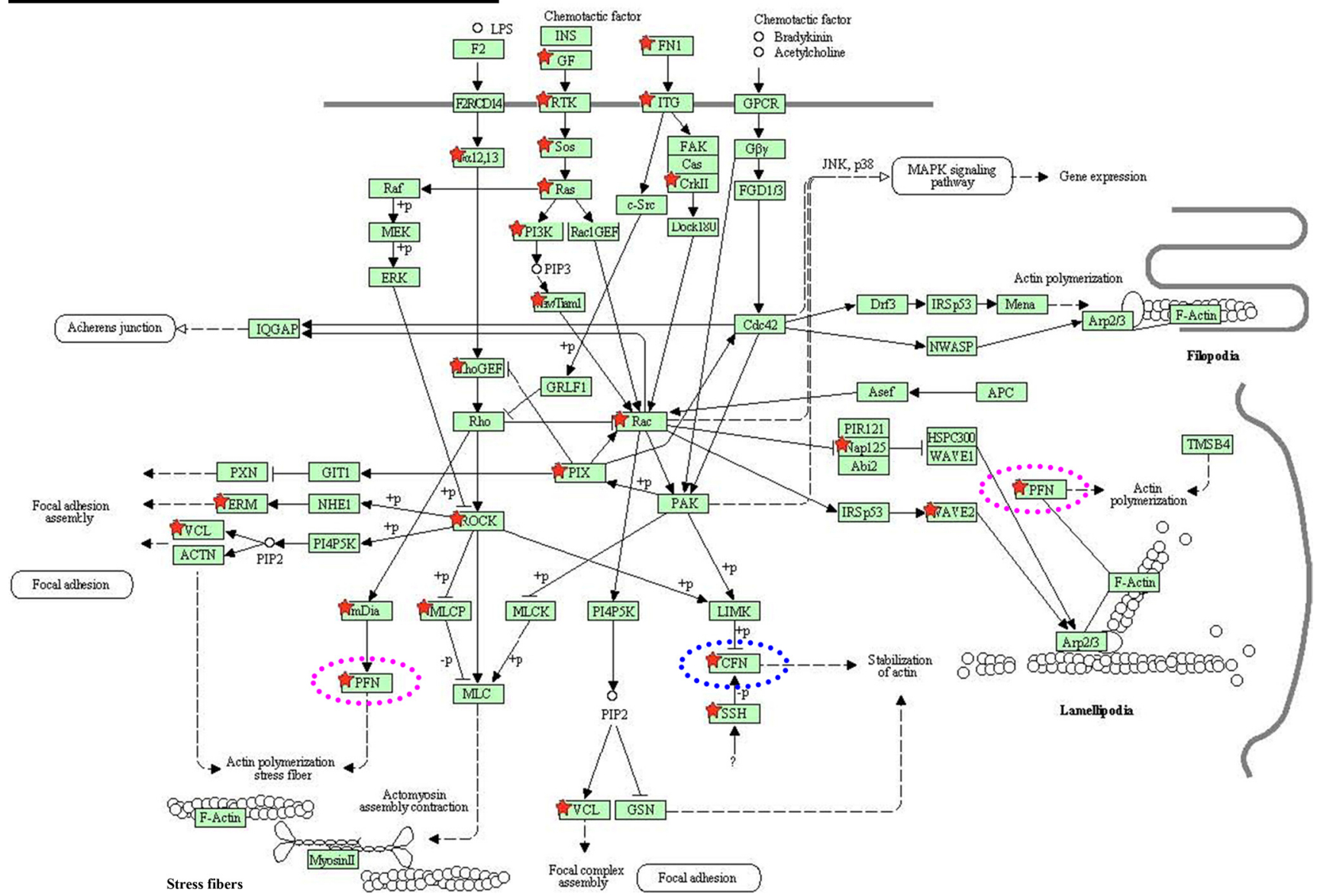

FIG. 5. A scheme showing how DDX5 regulates actin cytoskeleton via miR-182. DDX5 directly regulates expression of a subset of miRNAs including miR-182, which in turn regulates the actin cytoskeleton dynamics through its predicted downstream targets (labeled with red stars), such as cofilin (CFN, circled with blue dots) and profilin (PFN, circled with pink dots). The process is modulated by the interactome and post-translational modifications ("PTMs") of DDX5. Pathways and networks were generated using DAVID, KEGG, and STRING. 
cells and impacts DNA repair and sensitivity to PARP inhibitors (54). This is consistent with our data showing that DDX5 expresses predominantly at high levels in basal breast cancer cells and up-regulates miR-182. Furthermore, this suggests an intriguing possibility that DDX5 downregulates $B R C A 1$ indirectly via miR-182, i.e. through the DDX5 $\rightarrow$ miR-182 $\rightarrow$ BRCA1 pathway, thus confirming the critical importance of DDX5 in breast cancer. Future work is clearly warranted to test whether miR-182 promotes tumorigenesis and metastasis in vivo.

Our study has implications for breast cancer treatment. Currently, there is no effective targeted therapy for triplenegative tumors. We demonstrate that DDX5 up-regulates miRNAs such as miR-21 and miR-182. Therefore, targeting DDX5 and/or its downstream miRNAs might be a novel strategy for treating this tumor subtype. ERBB2 is overexpressed in $20 \sim 30 \%$ of invasive breast tumors. We observed a positive correlation between DDX5 and ErbB2 in invasive breast cancers. However, knockdown of ErbB2 in ErbB2+ breast cancer cell lines didn't affect DDX5 protein expression, and vice versa (data not shown). ERBB2 signaling up-regulates miR-21 and promotes cell invasion (55). We show that DDX5 also up-regulates miR-21. Therefore, DDX5 and ErbB2 might work cooperatively to control miR-21 levels in vivo in a context-dependent manner, e.g. according to the tumor ERBB2 status and tissue microenvironment. Because breast tumors are highly heterogeneous, a subpopulation of ErbB2 ${ }^{\text {low }} / \mathrm{DDX} 5^{\text {high }}$ cells may exist even within the ERBB2 + tumors. Presumably, the DDX5 ${ }^{\text {high }}$ cells possess the above-mentioned "stem-cell like" properties which confer invasiveness and drug resistance. Therefore, it is tempting to speculate that a subpopulation of ErbB2 ${ }^{\text {low }} / D D X 5^{\text {high }}$ cells confers the resistance of ErbB2 + breast tumors to ErbB2-targeting drugs such as Lapatinib and Herceptin (trastuzumab). If this proves to be the case, then a combination therapy targeting ErbB2 plus DDX5 may be more efficient for treating ErbB2 + breast cancers. Indeed, DDX5 is druggable and serves as a direct target of (-)-Epigallocatechin-3-gallate in green tea, in suppressing the growth of human gastric cancer cells (56).

In summary, we have described a new functional role of RNA helicase DDX5 in basal breast cancer cells. Future work will elucidate mechanistically how DDX5 regulates specific miRNAs, validate the in vivo direct targets of miR-182 such as cofilin and profilin, and test the utility of DDX5 in serving as a new molecular marker for breast cancer theranostics.

Acknowledgments-We thank Drs. Ge Huang, Langxing Pan, Wen-Lin Kuo, Ming Dong, and Ms. Nora Bayani for technical assistance, and Dr. Joe Gray for discussions and for breast cancer cell lines.

\footnotetext{
* This work was supported by an IDEA grant from the California Breast Cancer Research Program (to D.W.), and in part by grant U24 CA126477 from the National Institutes of Health. It was performed
}

under the auspices of the DOE, at the University of California/ Lawrence Berkeley National Laboratory under contract No. DEAC02-05CH11231.

S This articles contains supplemental Figs. S1 and S2.

I To whom correspondence should be addressed: Daojing Wang, Ph.D., Life Sciences Division, Lawrence Berkeley National Laboratory, 1 Cyclotron Road, MS 977, Berkeley, CA 94720. Tel.: 510-486-6592; Fax: 510-495-2535; E-mail: djwang@lbl.gov.

\section{REFERENCES}

1. Polyak, K. (2007) Breast cancer: origins and evolution. J. Clin. Invest. 117, 3155-3163

2. Perou, C. M., Sorlie, T., Eisen, M. B., van de Rijn, M., Jeffrey, S. S., Rees, C. A., Pollack, J. R., Ross, D. T., Johnsen, H., Akslen, L. A., Fluge, O., Pergamenschikov, A., Williams, C., Zhu, S. X., Lonning, P. E., BørresenDale, A. L., Brown, P. O., and Botstein, D. (2000) Molecular portraits of human breast tumours. Nature 406, 747-752

3. Hu, Z., Fan, C., Oh, D. S., Marron, J. S., He, X., Qaqish, B. F., Livasy, C., Carey, L. A., Reynolds, E., Dressler, L., Nobel, A., Parker, J., Ewend, M. G., Sawyer, L. R., Wu, J., Liu, Y., Nanda, R., Tretiakova, M., Ruiz Orrico, A., Dreher, D., Palazzo, J. P., Perreard, L., Nelson, E., Mone, M., Hansen, H., Mullins, M., Quackenbush, J. F., Ellis, M. J., Olopade, O. I., Bernard, P. S., and Perou, C. M. (2006) The molecular portraits of breast tumors are conserved across microarray platforms. BMC Genomics $\mathbf{7}$, 96

4. Parker, J. S., Mullins, M., Cheang, M. C., Leung, S., Voduc, D., Vickery, T., Davies, S., Fauron, C., He, X., Hu, Z., Quackenbush, J. F., Stijleman, I. J., Palazzo, J., Marron, J. S., Nobel, A. B., Mardis, E., Nielsen, T. O., Ellis, M. J., Perou, C. M., and Bernard, P. S. (2009) Supervised risk predictor of breast cancer based on intrinsic subtypes. J. Clin. Oncol. 27, $1160-1167$

5. Cleator, S., Heller, W., and Coombes, R. C. (2007) Triple-negative breast cancer: therapeutic options. Lancet Oncol. 8, 235-244

6. Al-Hajj, M., Wicha, M. S., Benito-Hernandez, A., Morrison, S. J., and Clarke, M. F. (2003) Prospective identification of tumorigenic breast cancer cells. Proc. Natl. Acad. Sci. U.S.A. 100, 3983-3988

7. Wang, D., and Bodovitz, S. (2010) Single cell analysis: the new frontier in 'omics'. Trends Biotechnol. 28, 281-290

8. Causevic, M., Hislop, R. G., Kernohan, N. M., Carey, F. A., Kay, R. A., Steele, R. J., and Fuller-Pace, F. V. (2001) Overexpression and polyubiquitylation of the DEAD-box RNA helicase p68 in colorectal tumours. Oncogene 20, 7734-7743

9. Shin, S., Rossow, K. L., Grande, J. P., and Janknecht, R. (2007) Involvement of RNA helicases p68 and p72 in colon cancer. Cancer Res. 67, 7572-7578

10. Clark, E. L., Coulson, A., Dalgliesh, C., Rajan, P., Nicol, S. M., Fleming, S., Heer, R., Gaughan, L., Leung, H. Y., Elliott, D. J., Fuller-Pace, F. V., and Robson, C. N. (2008) The RNA helicase p68 is a novel androgen receptor coactivator involved in splicing and is overexpressed in prostate cancer. Cancer Res. 68, 7938-7946

11. Wortham, N. C., Ahamed, E., Nicol, S. M., Thomas, R. S., Periyasamy, M., Jiang, J., Ochocka, A. M., Shousha, S., Huson, L., Bray, S. E., Coombes, R. C., Ali, S., and Fuller-Pace, F. V. (2009) The DEAD-box protein p72 regulates ERalpha-/oestrogen-dependent transcription and cell growth, and is associated with improved survival in ERalpha-positive breast cancer. Oncogene 28, 4053-4064

12. Mooney, S. M., Grande, J. P., Salisbury, J. L., and Janknecht, R. (2010) Sumoylation of p68 and p72 RNA helicases affects protein stability and transactivation potential. Biochemistry 49, 1-10

13. Lu, J., Getz, G., Miska, E. A., Alvarez-Saavedra, E., Lamb, J., Peck, D., Sweet-Cordero, A., Ebert, B. L., Mak, R. H., Ferrando, A. A., Downing, J. R., Jacks, T., Horvitz, H. R., and Golub, T. R. (2005) MicroRNA expression profiles classify human cancers. Nature 435, 834-838

14. He, L., He, X., Lim, L. P., de Stanchina, E., Xuan, Z., Liang, Y., Xue, W., Zender, L., Magnus, J., Ridzon, D., Jackson, A. L., Linsley, P. S., Chen, C., Lowe, S. W., Cleary, M. A., and Hannon, G. J. (2007) A microRNA component of the p53 tumour suppressor network. Nature 447, 1130-1134

15. Ma, L., Teruya-Feldstein, J., and Weinberg, R. A. (2007) Tumour invasion and metastasis initiated by microRNA-10b in breast cancer. Nature $\mathbf{4 4 9}$, 
$682-688$

16. Tavazoie, S. F., Alarcon, C., Oskarsson, T., Padua, D., Wang, Q., Bos, P. D., Gerald, W. L., and Massagué, J. (2008) Endogenous human microRNAs that suppress breast cancer metastasis. Nature 451, 147-152

17. Fukuda, T., Yamagata, K., Fujiyama, S., Matsumoto, T., Koshida, I., Yoshimura, K., Mihara, M., Naitou, M., Endoh, H., Nakamura, T., Akimoto, C., Yamamoto, Y., Katagiri, T., Foulds, C., Takezawa, S., Kitagawa, H., Takeyama, K., O'Malley, B. W., and Kato, S. (2007) DEAD-box RNA helicase subunits of the Drosha complex are required for processing of rRNA and a subset of microRNAs. Nat. Cell. Biol. 9, 604-611

18. Suzuki, H. I., Yamagata, K., Sugimoto, K., Iwamoto, T., Kato, S., and Miyazono, K. (2009) Modulation of microRNA processing by p53. Nature 460, 529-533

19. Neve, R. M., Chin, K., Fridlyand, J., Yeh, J., Baehner, F. L., Fevr, T., Clark, L., Bayani, N., Coppe, J. P., Tong, F., Speed, T., Spellman, P. T., DeVries, S., Lapuk, A., Wang, N. J., Kuo, W. L., Stilwell, J. L., Pinkel, D., Albertson, D. G., Waldman, F. M., McCormick, F., Dickson, R. B., Johnson, M. D., Lippman, M., Ethier, S., Gazdar, A., and Gray, J. W. (2006) A collection of breast cancer cell lines for the study of functionally distinct cancer subtypes. Cancer Cell 10, 515-527

20. Wang, D., and Jang, D. J. (2009) Protein kinase CK2 regulates cytoskeletal reorganization during ionizing radiation-induced senescence of human mesenchymal stem cells. Cancer Res. 69, 8200-8207

21. Livak, K. J., and Schmittgen, T. D. (2001) Analysis of relative gene expression data using real-time quantitative PCR and the 2(-Delta Delta $\mathrm{C}(\mathrm{T})$ ) Method. Methods 25, 402-408

22. Jang, D. J., Guo, M., and Wang, D. (2007) Proteomic and biochemical studies of calcium- and phosphorylation-dependent calmodulin complexes in Mammalian cells. J. Proteome Res. 6, 3718-3728

23. Ritchie, M. E., Silver, J., Oshlack, A., Holmes, M., Diyagama, D., Holloway, A., and Smyth, G. K. (2007) A comparison of background correction methods for two-colour microarrays. Bioinformatics 23, 2700-2707

24. Endoh, H., Maruyama, K., Masuhiro, Y., Kobayashi, Y., Goto, M., Tai, H., Yanagisawa, J., Metzger, D., Hashimoto, S., and Kato, S. (1999) Purification and identification of p68 RNA helicase acting as a transcriptional coactivator specific for the activation function 1 of human estrogen receptor alpha. Mol. Cell. Biol. 19, 5363-5372

25. Bates, G. J., Nicol, S. M., Wilson, B. J., Jacobs, A. M., Bourdon, J. C., Wardrop, J., Gregory, D. J., Lane, D. P., Perkins, N. D., and Fuller-Pace, F. V. (2005) The DEAD box protein p68: a novel transcriptional coactivator of the p53 tumour suppressor. EMBO J. 24, 543-553

26. Nielsen, T. O., Hsu, F. D., Jensen, K., Cheang, M., Karaca, G., Hu, Z., Hernandez-Boussard, T., Livasy, C., Cowan, D., Dressler, L., Akslen, L. A., Ragaz, J., Gown, A. M., Gilks, C. B., van de Rijn, M., and Perou, C. M. (2004) Immunohistochemical and clinical characterization of the basal-like subtype of invasive breast carcinoma. Clin. Cancer Res. 10, 5367-5374

27. Kalluri, R., and Weinberg, R. A. (2009) The basics of epithelial-mesenchymal transition. J. Clin. Invest. 119, 1420-1428

28. Zeisberg, M., and Neilson, E. G. (2009) Biomarkers for epithelial-mesenchymal transitions. J. Clin. Invest. 119, 1429-1437

29. Salzman, D. W., Shubert-Coleman, J., and Furneaux, H. (2007) P68 RNA helicase unwinds the human let-7 microRNA precursor duplex and is required for let-7-directed silencing of gene expression. J. Biol. Chem. 282, 32773-32779

30. Zhu, S., Wu, H., Wu, F., Nie, D., Sheng, S., and Mo, Y. Y. (2008) MicroRNA-21 targets tumor suppressor genes in invasion and metastasis. Cell Res. 18, 350-359

31. Frankel, L. B., Christoffersen, N. R., Jacobsen, A., Lindow, M., Krogh, A., and Lund, A. H. (2008) Programmed cell death 4 (PDCD4) is an important functional target of the microRNA miR-21 in breast cancer cells. J. Biol. Chem. 283, 1026-1033

32. Hatley, M. E., Patrick, D. M., Garcia, M. R., Richardson, J. A., Bassel-Duby, R., van Rooij, E., and Olson, E. N. (2010) Modulation of K-Ras-dependent lung tumorigenesis by MicroRNA-21. Cancer Cell 18, 282-293

33. Roa, W., Brunet, B., Guo, L., Amanie, J., Fairchild, A., Gabos, Z., Nijjar, T., Scrimger, R., Yee, D., and Xing, J. (2010) Identification of a new microRNA expression profile as a potential cancer screening tool. Clin. Invest. Med. 33, E124

34. Stevenson, R. J., Hamilton, S. J., MacCallum, D. E., Hall, P. A., and Fuller-Pace, F. V. (1998) Expression of the 'dead box' RNA helicase p68 is developmentally and growth regulated and correlates with organ differentiation/maturation in the fetus. J. Pathol. 184, 351-359

35. Fuller-Pace, F. V. (2006) DExD/H box RNA helicases: multifunctional proteins with important roles in transcriptional regulation. Nucleic Acids Res. 34, 4206-4215

36. Guo, H., Ingolia, N. T., Weissman, J. S., and Bartel, D. P. (2010) Mammalian microRNAs predominantly act to decrease target mRNA levels. Nature 466, 835-840

37. Yang, L., Lin, C., Sun, S. Y., Zhao, S., and Liu, Z. R. (2007) A double tyrosine phosphorylation of P68 RNA helicase confers resistance to TRAIL-induced apoptosis. Oncogene 26, 6082-6092

38. Mooney, S. M., Goel, A., D’Assoro, A. B., Salisbury, J. L., and Janknecht, R. (2010) Pleiotropic effects of p300-mediated acetylation on p68 and p72 RNA helicase. J. Biol. Chem. 285, 30443-30452

39. Jacobs, A. M., Nicol, S. M., Hislop, R. G., Jaffray, E. G., Hay, R. T., and Fuller-Pace, F. V. (2007) SUMO modification of the DEAD box protein p68 modulates its transcriptional activity and promotes its interaction with HDAC1. Oncogene 26, 5866-5876

40. Pavelic, Z. P., Pavelic, L., Lower, E. E., Gapany, M., Gapany, S., Barker, E. A., and Preisler, H. D. (1992) c-myc, c-erbB-2, and Ki-67 expression in normal breast tissue and in invasive and noninvasive breast carcinoma. Cancer Res. 52, 2597-2602

41. Scholzen, T., and Gerdes, J. (2000) The Ki-67 protein: from the known and the unknown. J. Cell. Physiol. 182, 311-322

42. de Azambuja, E., Cardoso, F., de Castro, G., Jr., Colozza, M., Mano, M. S., Durbecq, V., Sotiriou, C., Larsimont, D., Piccart-Gebhart, M. J., and Paesmans, M. (2007) Ki-67 as prognostic marker in early breast cancer: a meta-analysis of published studies involving 12,155 patients. $\mathrm{Br}$. J. Cancer 96, 1504-1513

43. Foulkes, W. D., Brunet, J. S., Stefansson, I. M., Straume, O., Chappuis, P. O., Bégin, L. R., Hamel, N., Goffin, J. R., Wong, N., Trudel, M., Kapusta, L., Porter, P., and Akslen, L. A. (2004) The prognostic implication of the basal-like (cyclin E high/p27 low/p53+/glomeruloid-microvascular-proliferation +) phenotype of BRCA1-related breast cancer. Cancer Res. 64, 830-835

44. Livasy, C. A., Karaca, G., Nanda, R., Tretiakova, M. S., Olopade, O. I., Moore, D. T., and Perou, C. M. (2006) Phenotypic evaluation of the basal-like subtype of invasive breast carcinoma. Mod. Pathol. 19, 264-271

45. Urruticoechea, A., Smith, I. E., and Dowsett, M. (2005) Proliferation marker Ki-67 in early breast cancer. J. Clin. Oncol. 23, 7212-7220

46. Cohen, A. A., Geva-Zatorsky, N., Eden, E., Frenkel-Morgenstern, M., Issaeva, I., Sigal, A., Milo, R., Cohen-Saidon, C., Liron, Y., Kam, Z., Cohen, L., Danon, T., Perzov, N., and Alon, U. (2008) Dynamic proteomics of individual cancer cells in response to a drug. Science 322, 1511-1516

47. Medina, P. P., Nolde, M., and Slack, F. J. (2010) OncomiR addiction in an in vivo model of microRNA-21-induced pre-B-cell lymphoma. Nature 467, 86-90

48. Segura, M. F., Hanniford, D., Menendez, S., Reavie, L., Zou, X., AlvarezDiaz, S., Zakrzewski, J., Blochin, E., Rose, A., Bogunovic, D., Polsky, D., Wei, J., Lee, P., Belitskaya-Levy, I., Bhardwaj, N., Osman, I., and Hernando, E. (2009) Aberrant miR-182 expression promotes melanoma metastasis by repressing $\mathrm{FOXO} 3$ and microphthalmiaassociated transcription factor. Proc. Natl. Acad. Sci. U.S.A. 106, 1814-1819

49. Guttilla, I. K., and White, B. A. (2009) Coordinate regulation of FOXO1 by miR-27a, miR-96, and miR-182 in breast cancer cells. J. Biol. Chem. 284, 23204-23216

50. Barshack, I., Lithwick-Yanai, G., Afek, A., Rosenblatt, K., Tabibian-Keissar, H., Zepeniuk, M., Cohen, L., Dan, H., Zion, O., Strenov, Y., PolakCharcon, S., and Perelman, M. (2010) MicroRNA expression differentiates between primary lung tumors and metastases to the lung. Pathol. Res. Pract. 206, 578-584

51. Jiang, L., Mao, P., Song, L., Wu, J., Huang, J., Lin, C., Yuan, J., Qu, L., Cheng, S. Y., and Li, J. (2010) miR-182 as a prognostic marker for glioma progression and patient survival. Am. J. Pathol. 177, 29-38

52. Yamaguchi, H., and Condeelis, J. (2007) Regulation of the actin cytoskeleton in cancer cell migration and invasion. Biochim. Biophys. Acta 1773, 642-652

53. Wang, W., Eddy, R., and Condeelis, J. (2007) The cofilin pathway in breast cancer invasion and metastasis. Nat. Rev. Cancer 7, 429-440 
54. Moskwa, P., Buffa, F. M., Pan, Y., Panchakshari, R., Gottipati, P., Muschel, R. J., Beech, J., Kulshrestha, R., Abdelmohsen, K., Weinstock, D. M., Gorospe, M., Harris, A. L., Helleday, T., and Chowdhury, D. (2011) miR-182-mediated downregulation of BRCA1 impacts DNA repair and sensitivity to PARP inhibitors. Mol. Cell 41, 210-220

55. Huang, T. H., Wu, F., Loeb, G. B., Hsu, R., Heidersbach, A., Brincat, A., Horiuchi, D., Lebbink, R. J., Mo, Y. Y., Goga, A., and McManus, M. T.
(2009) Up-regulation of miR-21 by HER2/neu signaling promotes cell invasion. J. Biol. Chem. 284, 18515-18524

56. Tanaka, T., Ishii, T., Mizuno, D., Mori, T., Yamaji, R., Nakamura, Y., Kumazawa, S., Nakayama, T., and Akagawa, M. (2011) (-)-Epigallocatechin-3-gallate suppresses growth of AZ521 human gastric cancer cells by targeting the DEAD-box RNA helicase p68. Free Radic. Biol. Med. 50, $1324-1335$ 